\title{
(RE)POLITIZANDO O CONCEITO DE GÊNERO: A PARTICIPAÇÃO POLÍTICA DAS MULHERES NO MST
}

\author{
Renata Gonçalves ${ }^{1}$
}

\begin{abstract}
Resumo
Neste artigo procuramos examinar a complexa e contraditória construção do Setor de Gênero como parte da estrutura organizativa do Movimento dos Trabalhadores Rurais Sem Terra (MST). 0 pano de fundo são as tensões em torno da participação política das mulheres na luta pela terra, em que a ênfase inicial dada à categoria mulher vai sendo substituída pela de gênero. Mais do que simples alterações na nomenclatura, trata-se do desafio de compreender teoricamente e construir, na prática política, novas relações de gênero. Na contramão de um uso cada vez mais academicista, este processo acena para a (re)politização do conceito de gênero.
\end{abstract}

Palavras-chave: MST. Mulheres. Relações de Gênero.

\section{(RE) POLITICIZING THE CONCEPT OF GENDER: THE POLITICAL PARTICIPATION OF THE WOMEN IN THE MST}

\begin{abstract}
In this article we examine the complex and contradictory construction of the Gender Sector as a part of the organizational structure of the Movement of Landless

\footnotetext{
${ }^{1}$ Professora do Departamento e do Programa de Ciências Sociais, Centro de Letras e Ciências Humanas, da Universidade Estadual de Londrina. Pesquisadora do Grupo de Estudos de Política da América Latina (GEPAL), nesta mesma Universidade, e do Núcleo de Estudos de Ideologias e Lutas Sociais (NEILS), sediado no Programa de Estudos Pós-Graduados em Ciências Sociais da PUC-SP End. eletrônico: rengon@terra.com.br
}

198 • Recebido em 15 de novembro de 2009. Aceito em 17 de dezembro de 2009. 
Rural Workers (MST). The background is formed by the tensions surrounding the political participation of women in the struggle for land, in which the initial emphasis given to the category woman is substituted by the concept of gender. More than a simple alteration in terminology, this change involves the challenge of understanding theoretically and constructing in political practice new gender relations.

Keywords: MST. Women. Gender relations.

\section{INTRODUÇÃO}

C ompreender a presença das mulheres no Movimento dos Trabalhadores Rurais Sem Terra implica distinguir diferentes espaços de participação, cujos principais e mais conhecidos são: 1) a ocupação, quando com frequência estão na linha de frente nos confrontos armados com 0 aparato repressivo "clandestino" e/ou estatal; 2) o acampamento, onde, apesar das constantes e violentas investidas dos jagunços das fazendas, há uma maior participação política das mulheres e quando se vive o mais próximo de uma igualdade entre os sexos; e 3) o assentamento, quando percebemos um recuo das mulheres para a chamada esfera doméstica.

$\mathrm{Na}$ impossibilidade de reproduzir aqui um estudo minucioso de como as mulheres participam nos vários espaços do MST, optamos por retraçar o trajeto da construção de um espaço de participação muito pouco estudado e que, no entanto, é o pilar das diferentes formas de organização das mulheres no interior do MST: o Setor de Gênero ${ }^{2}$. Este setor, assim como os vários outros, estabelece os laços entre ocupação, acampamento e assentamento e é igualmente produto das e o ponto de partida para as reflexões acerca da politização e ação das mulheres no Movimento. Neste sentido, está não somente entranhado na estrutura organizativa nacional, como também é fonte de reflexão e debates constantes nas instâncias regionais.

Sabemos dos limites que esta opção nos impõe, mas a escolha deste caminho metodológico nos permitirá compreender a participação das mulheres tanto nas esferas de decisão como nas repercussões junto às bases do Movimento.

As fontes às quais recorremos para a elaboração deste texto foram, sobretudo, os inúmeros documentos confeccionados pelos cursos de formação do Movimento

${ }^{2}$ Todos os grifos ao longo deste artigo são nossos. 
nas instâncias nacional e regionais. Utilizamos também neste artigo as entrevistas realizadas com algumas lideranças do Setor de Gênero nacional e da regional do Pontal do Paranapanema-SP ${ }^{3}$, além das observações em diversos assentamentos e acampamentos do MST nos estados de São Paulo, Paraná e Maranhão.

Ainda com relação às fontes, cabe uma ressalva quanto às diferenças regionais encontradas em vários estados em que o movimento atua. No entanto, os documentos nacionais e os inúmeros trabalhos (teses, dissertações, artigos, livros, etc.) a que tivemos acesso, nos permitem observar que nas mais diversas regiões, guardadas as devidas proporções, tanto as formas como os obstáculos à participação das mulheres no MST são muito semelhantes.

\section{A ÁrduA MARCHA RUMO À CONSTRUÇÃO DO SETOR DE GÊNERO}

0 reconhecimento da necessidade de participação das mulheres no MST é fruto de um processo complexo e contraditório ainda em andamento. Na fase inicial o movimento se debruça muito pouco sobre as chamadas questões de gênero e em suas primeiras publicações, a preocupação com a formação das mulheres é nula. A chamada "questão da mulher" ou estava ausente ou era tratada como assunto interno e, portanto, não necessitava ser publicizada (SILVA, 2004, p. 40).

Apesar disso, ainda nos anos 1980, quando pouco se sabia sobre este movimento, foi organizada uma Comissão Nacional de Mulheres do MST, a qual pressionou para que houvesse grupos de mulheres dentro dos acampamentos e assentamentos de cada estado. Reivindicava também que as lideranças nos estados e nos assentamentos apoiassem as organizações das mulheres dentro do movimento. Em setembro de 1989, já na primeira edição das Normas gerais do MST, se incluiu um capítulo sobre a "articulação das mulheres", com destaque para "a luta contra todas as formas de discriminação e contra o machismo", além de chamar a atenção para a necessidade de "organizar uma comissão de mulheres em nível nacional, responsável pelas políticas propostas para o movimento" (MST, 1989, Cap. VIII).

Pavan (1998) observava que apesar dos incentivos impressos nos documentos do MST, a presença feminina nas instâncias de poder era pequena. Embora não haja uma sistematização dos dados sobre a atuação das mulheres

${ }^{3}$ Palco central de nossa pesquisa de doutorado. Ver Gonçalves (2005). 
nas direções nacional, estaduais e regionais, líderes do movimento garantem que ela está crescendo desde o final dos anos 1990. Em entrevista concedida ao jornal cearense 0 povo, Christiane Campos, assentada do Rio Grande do Sul e coordenadora do Setor de Gênero do MST, enfatizou que "as mulheres têm sido 30\% da direção nacional. Nos estados, isso varia muito, mas, em média, representam 40\%” (BONFIN, 2002).

0 que podemos encontrar por trás dos números concernentes à presença das mulheres nas instâncias decisórias? Qual a relação entre a proposta incentivadora e a efetiva participação das mulheres? Responder a estas questões implica antes de tudo entender a estrutura organizativa do Movimento.

No organograma do MST constam uma Coordenação Nacional, composta por militantes representantes dos estados; uma Direção Nacional, formada por um representante por estado. A cada cinco anos ocorrem os Congressos Nacionais, instância máxima do Movimento, com debates para definir uma linha de atuação comum para o conjunto do MST. Os debates maiores ocorrem nos Encontros anuais dos estados e das regiões quando são eleitas, em cada um dos níveis, suas Coordenação e Direção. Ali são estabelecidas as prioridades e diretrizes com uma metodologia adequada à realidade regional.

É nos Encontros estaduais e regionais que se discute a estruturação dos setores, compostos por militantes acampado(a)s e assentado(a)s que tanto configuram a base do MST como fazem o vínculo com as coordenações e direções estaduais e nacionais.

Para Franco (2004), os principais setores são: Frente de Massas (planeja as ocupações e dirige os acampamentos); Produção (atua na organização da produção nos assentamentos); Educação (organiza escolas nos acampamentos e assentamentos); Comunicação (divulga boletins na imprensa e incentiva as rádios comunitárias nos assentamentos); Cultura (promove a cultura camponesa e o fomento de atividades culturais e esportivas no meio rural); Saúde (acompanha as carências básicas no âmbito da saúde nos acampamentos e assentamentos); Formação (encarrega-se do aprofundamento político e ideológico das bases acampadas e assentadas); Gênero (responsável em organizar os Coletivos de Gênero e mobilizar politicamente as mulheres nos acampamentos e assentamentos).

Os setores dão sustentação à estrutura organizativa do MST e foram surgindo de acordo com as necessidades, enfrentamentos, debates, vivências ao 
longo da luta pela terra (STÉDILE \& FERNANDES, 1999). Com o de gênero não foi diferente. Embora seja apresentado como o setor responsável pela organização política das mulheres, são muitas as tensões em torno da criação deste setor e, por conseguinte, da participação feminina nas diferentes instâncias de poder do movimento.

Se na fase inicial do MST a preocupação com a presença das mulheres é quase nula, paulatinamente, nos anos 1990 começou a ser criado um Coletivo Nacional de Mulheres do MST. A "invisibilidade" da participação feminina passou a ser o objeto de debates e resoluções. No artigo 45 do Documento Básico do MST, de 1993, é enfatizada a necessidade de "Considerar as questões específicas das mulheres e sua participação como parte integrante das reivindicações e da organização, tratando como classe e não enquanto gênero"; além disso, no artigo 152, ressalta-se que é preciso "garantir a participação das mulheres em todos os níveis da cooperação agrícola e sobretudo estimular sua participação no trabalho produtivo, como também combater as desigualdades e o tradicionalismo que existe no meio camponês". Com efeito, são muitos os depoimentos e textos que se referem ao meio camponês como sendo um lugar de permanência do machismo e de recuo político das mulheres. Campos, por exemplo, em sua entrevista ao jornal O Povo, dizia que guardadas as especificidades regionais, pois o Sul e o Nordeste contam com maior inserção feminina, "o que se percebe é que o machismo é muito maior no meio rural e o MST trabalha justamente com esse público" (BONFIN, 2002). Os lutadores camponeses sem-terra quando transformados em assentados parecem se tornar mais machistas e o recuo da participação política das mulheres é uma constante. As entrevistas realizadas por Cristiani Bereta da Silva em assentamentos do estado de Santa Catarina revelam "que a 'pouca' participação feminina era um problema que o movimento precisava resolver" (2004a, p. 270). À mesma conclusão chegam as ativistas entrevistadas por Carmen Deere. Para estas, "depois da conquista da terra, nos assentamentos, um grande número de mulheres volta a fazer apenas trabalho interno, na roça, em casa ou com as crianças. Por isso, é necessário que as mulheres se organizem e participem da luta da classe trabalhadora em todas as instâncias" (DEERE, 2004, p. 186-187).

Isto significa que a instância decisória do MST tem de lidar com os problemas encontrados junto à sua base, sobretudo nos assentamentos onde predominam a lealdade à tradição ao lado de uma dinâmica conservadora da organização social (WOORTMANN, 2004). Nos assentamentos, enquanto os homens vão para a roça, as mulheres ficam em casa cuidando das atividades domésticas, tal como 
no processo de "socialização dos corpos", identificado por Esmeraldo, em que o corpo masculino se estruturará no fora e no produtivo e "o corpo da mulher se socializará na casa, no uso de um tempo que parece se eternizar em um trabalho - o doméstico, que a cada dia é retomado, em uma rotina e ordens constantes" (ESMERALDO, 2008, p. 199).

Observa-se, sobretudo no espaço dos assentamentos, uma relação de hierarquia entre os gêneros, uma valorização diferente do trabalho das mulheres, mesmo quando estas exercem as mesmas atividades que os homens ${ }^{4}$. Esta "tradição" nos assentamentos é reforçada pela divisão sexual explícita no próprio contrato de concessão da gleba: o homem aparece como responsável pelo lote ao passo que a mulher é uma "dependente". A este respeito os estudos de Deere (2004) revelam que a

discriminação contra a mulher era tal que os funcionários do INCRA tomaram por certo que mulheres sem marido ou companheiro eram incapazes de administrar uma gleba, a menos que elas tivessem um filho maior, e não era incomum para mulheres que enviuvavam com crianças pequenas perderem seu direito a permanecer no assentamento de reforma agrária. Além disso, quando o filho mais velho da viúva era nomeado beneficiário, ela algumas vezes perdia 0 acesso à terra quando ele casava e formava sua própria família (DEERE, 2004, p. 184).

Funcionários do INCRA justificam este alijamento referindo-se à falta de espaço no cadastro para colocar o nome do homem e o da mulher. A Constituição de 1988 registra algumas mudanças com relação às beneficiárias da reforma agrária ao estabelecer "peso igual para o trabalho de homens e mulheres no sistema de pontuação usado para selecionar os beneficiários" (DEERE, 2004, p. 185). Todavia, funcionários do INCRA, recorrendo, inconscientemente ou não, ao velho princípio liberal do direito incluído, argumentam que "o objetivo da reforma agrária é beneficiar famílias e ao beneficiá-las - como representadas pelo chefe de família - eles estão beneficiando todos os membros dentro delas" (DEERE, 2004, p. 186).

Apesar da existência da Portarian. 891, de 2003, do INCRA que regulamenta a titulação conjunta e obrigatória da terra, o cotidiano dos assentamentos é pautado

\footnotetext{
${ }^{4}$ Os estudos de Paulilo (1987) já enfatizaram esta assimetria, que distingue o trabalho leve do trabalho pesado de acordo com o sexo de quem o executa. São leves os trabalhos realizados pelas mulheres, mesmo quando aram a terra, puxam o burro no "muque" ou ocupam o mesmo volume de horas que os homens, ao passo que sãopesados aqueles feitos pelos homens.
} 
pela legislação sobre a reforma agrária que vigorou até 1985 e que se baseou no "Estatuto da Terra", de 1964. A prioridade dada a chefes de famílias maiores que quisessem dedicar-se às atividades agrícolas, fortaleceu critérios discriminatórios para as mulheres, pois "segundo as normas culturais, se um homem reside na casa, ele é sempre considerado seu chefe, uma norma apoiada no Código Civil de 1916" (DEERE, 2004, p. 184). Romper com esta prática discriminatória não é tarefa das mais fáceis. A tão sonhada e conquistada Portaria que garante a participação das mulheres na titularidade da terra tem pouco efeito sobre a estrutura de poder masculino: ainda cabem aos homens as atividades consideradas produtivas, enquanto aquelas atividades desempenhadas pelas mulheres são consideradas "não-produtivas" (BRUMER \& ANJOS, 2008).

Estas e inúmeras outras questões que dizem respeito ao cotidiano de homens e mulheres envolvidos na luta pela terra são pano de fundo para os debates acerca da participação das mulheres no MST e conduziram a outras intensas discussões que proporcionaram, num primeiro momento, a criação de um Coletivo Nacional de Mulheres do MST; seguido do Coletivo Nacional de Gênero e, finalmente, do Setor Nacional de Gênero. Estas mudanças, para além de simples alterações na nomenclatura, parecem acompanhar as transformações provocadas pelas mais diversas experiências vividas pelas mulheres (e também por homens) nas diferentes esferas do Movimento.

\section{DE COMPANHEIRA “ACOMPANHANTE”}

\section{À COMPANHEIRA DE LUTA}

Os inúmeros textos produzidos pelo MST expressam a dinâmica por que passou o debate acerca da participação das mulheres no Movimento. Estas apareciam num primeiro momento como membro da família. No período inicial, causava estranhamento a ideia de "um homem ir para a terra sozinho, tinha que acompanhá-lo, a mulher e os filhos". Acompanhar era a principal função das mulheres, com vistas a "'segurar' o homem no acampamento" (BOGO, 2003, p. 12). Mas, ao contrário da imagem pejorativa de que eram "coordenadoras de panelas", a própria dinâmica da luta pela terra as levou a organizar ações que, por sua vez, provocaram alguns questionamentos sobre a estrutura de poder expressa na organicidade do Movimento. Portanto, não parece ser obra do acaso

${ }^{5}$ A este respeito, consultar Rua e Abramovay (2000). 
se os Coletivos de Mulheres ou de Gênero e o Setor de Gênero só passaram a existir na segunda metade dos anos 1990.

Remonta a 1995, o I Encontro de Mulheres Trabalhadoras Rurais, reunindo mulheres de várias organizações rurais, onde se discutiu a necessidade de incorporação dos direitos já conquistados pelas trabalhadoras urbanas, como salário-maternidade, auxílio acidente de trabalho, etc. No Jornal Sem Terra, de novembro de 1995, ficam claras as influências deste Encontro para o MST. Lemos que gênero e classe se entrelaçam e "esta combinação de luta é fundamental não só para a construção de novas relações de gênero, mas de um projeto de sociedade democrática e popular" (JST, 1995, p. 12).

Em 1996 surgiu a primeira cartilha organizada pelo Coletivo Nacional de Mulheres. Sob o títuloA questão da mulher no MST, apresentava um plano de trabalho oriundo do Encontro Nacional das Mulheres Militantes do MST, realizado de 25 a 28 de maio daquele ano ${ }^{6}$. Segundo a cartilha, as mulheres enfrentam discriminação nos acampamentos e assentamentos e sentem a necessidade de uma estrutura que possibilite a participação delas. Salientam que, embora as mulheres lutem, não se sentem representadas. Além disso, refere-se à distância entre a teoria e a prática do movimento, que considera secundário 0 trabalho com e sobre as mulheres.

Para o Coletivo, as causas dos problemas estão não apenas na sociedade como no próprio MST, onde "a maioria acha que não existe problema", não cria mecanismos de participação e não investe na qualidade de formação nesta área. Por outro lado, o Coletivo identifica que as próprias mulheres também são responsáveis, na medida em que "têm medo de enfrentar os problemas" (COLETIVO NACIONAL DE MULHERES D0 MST, 1996, p. 3).

Apesar destas dificuldades, reconhece-se que houve avanços, dentre os quais está a conscientização de que se trata de um problema de caráter político e que é necessário estabelecer a relação entre gênero e luta de classes. A questão adquire maior seriedade e passa a ser mais problematizada.

Os desafios para o Coletivo Nacional de Mulheres eram muitos, desde questões sobre como construir novos valores, novas relações no cotidiano, passando por pensar no modo como atingir algumas metas, tais como "criar condições

\footnotetext{
${ }^{6}$ Em março de 1996, o Jornal Sem Terra havia chamado a atenção para a dupla exploração (de classe e de gênero) das mulheres e concluía que "O MST deve lutar também contra o machismo" (JST, 1996: 4).
} 
objetivas"; "pensar e propor formação política". E se alertava que "o número é importante, mas não suficiente" (COLETIVO..., 1996, p. 4), o que significa que os problemas não se resolvem com a introdução de cotas.

Uma das tarefas Coletivo consistia em fazer com que nas Instâncias do MST "todos os setores discutam e encaminhem concretamente a questão de gênero" (COLETIVO..., 1996, p. 8). Ao que parece responder o Setor de Formação (um dos pilares da militância do MST), pois, apenas dois meses após o Encontro Nacional de Mulheres, este setor, juntamente com os de educação e comunicação do Paraná, lança, em julho de 1996, a cartilha Sem mulher a luta vai pela metade. Num primeiro momento, o(a)s organizadore(a)s da cartilha afirmam que esta "foi escrita para as mulheres acampadas e assentadas, com o objetivo de ser mais um instrumento que contribui em sua organização"; e afirmam que buscam "colocar questões que estão no seu dia-a-dia mas que infelizmente, nunca ou poucas vezes discutimos ou conversamos" (COLETIVO..., 1996, p. 8).

Em seguida, anunciam que outro objetivo da cartilha é realizar encontros que "propiciem espaços para a criação de coletivos, que juntamente com os nossos companheiros homens, vamos debater e buscar soluções para 0 problema de nossa organização que é o MOVIMENTO SEM TERRA" (SETOR DE EDUCAÇÃO..., 1996, p. 1).

Para além dos planos e estratégias traçadas pelo Coletivo Nacional de Mulheres, podemos perceber que aos poucos vão sendo deixadas para trás as chamadas "questões das mulheres" e são introduzidas as "questões de gênero" como uma categoria mais abrangente e não para substituir a categoria "mulher".

\section{O FAZER-SE DE NOVAS RELAÇÕES DE GÊNERO}

A "questão de gênero" foi mais declaradamente assumida na cartilha seguinte, de 1998, com o significativo título de Compreender e construir novas relaçães de gênero. A apresentação de abertura da coletânea é atribuída ao novo Coletivo Nacional de Gênero, para quem a publicação deve servir "de documento permanente de estudo e aprofundamento entre a militância do MST, para compreendermos e construirmos novas relações de gênero no nosso dia-adia" (1998, p. 5). Todavia, o texto principal da coletânea ainda é assinado pelo antigo Coletivo Nacional de Mulheres, onde lemos que o papel das mulheres no MST "é o mesmo papel político desempenhado pelos homens, porém do jeito da 
mulher [sic], ou seja é o papel de atriz política, com sua característica de gênero feminino e de classe trabalhadora e que, por assim ser, é muito mais que estratégia para a resistência nas ações, e muito mais que esposa e mãe somente" (COLETIVO NACIONAL DE MULHERES, 1998, p. 49).

No ano de 2000 o agora existente Coletivo Nacional de Gênero lança a cartilha Mulher Sem Terra, com propostas de 8 reuniões ou encontros para "reunir as companheiras para estudar, debater, enfim, fortalecer a organicidade do MST" (COLETIVO NACIONAL DE GÊNERO, 2000, p. 4). A cartilha pretende fornecer elementos para a reflexão sobre a realidade e pretende que juntas, organizadas as mulheres busquem saídas para a construção de uma vida digna. Uma das orientações é a de "criar dinâmicas para envolver as mulheres para que participem, dêem sua contribuição e tentem melhorar o dia a dia no assentamento/ acampamento, seja no aspecto da produção, formação e participação" (COLETIV0 NACIONAL DE GÊNER0, 2000, p. 6). Propõe-se um tema a ser discutido em cada encontro, começando pelas "mulheres e a luta de classes", passando por "relações de gênero", "educar sem discriminar", "valores", "cultura e lazer nos assentamentos e acampamentos", "mulher e saúde", até chegar aos temas das "mulheres e a construção do projeto popular" e "as mulheres e a reforma agrária". A grande novidade é que, em linguagem simples e recorrendo a quadrinhos, busca-se explicar para as bases o que são relações de gênero, como ilustra a figura a seguir.

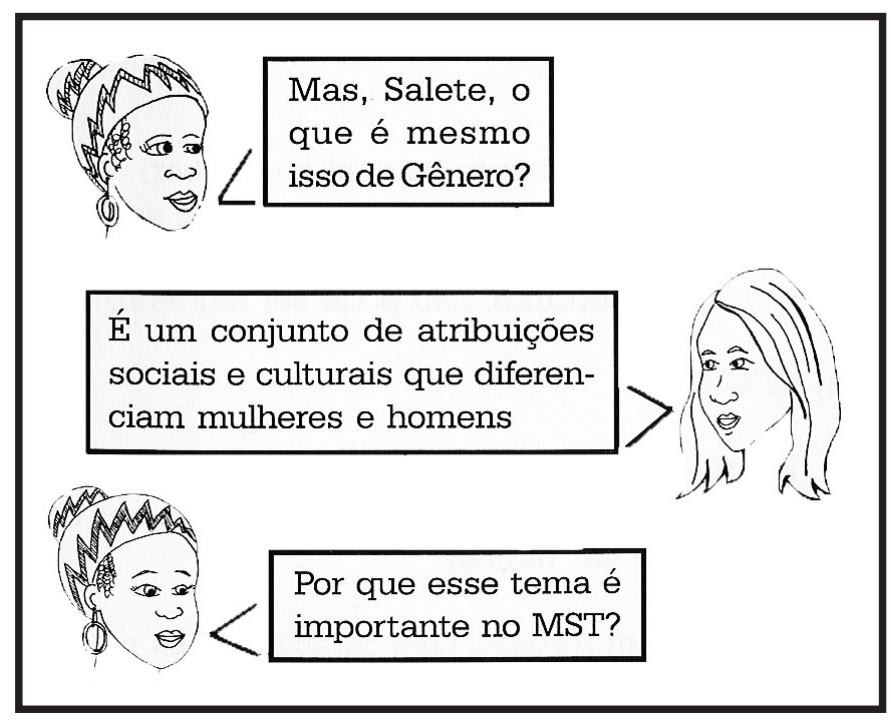

Fonte: Coletivo Nacional de Gênero, (2000, p. 13). 
Num evidente distanciamento do essencialismo expresso no "jeito de ser mulher", gênero passa a ser diferenciado de sexo, que é apresentado como característica biológica, relacionado à reprodução da espécie humana e, portanto, natural. Gênero passa a ser considerado uma construção social ou "uma etiqueta que a sociedade nos impõe do que é ser homem ou ser mulher" (COLETIVO NACIONAL DE GÊNERO, 2000, p. 14). A maneira de viver na sociedade como mulheres ou como homem é apreendida pelos costumes, pela cultura. Gênero "é cultural. Portanto pode e deve ser mudado!" (COLETIVO..., 2000, p. 15).

Em 2003, finalmente aparece a primeira cartilha elaborada pelo Setor Nacional de Gênero. A ênfase não está mais em "compreender", mas em "construir". Sob o título Construindo novas relações de gênero: desafiando relações de poder, esta cartilha adquire um caráter mais teórico e procura dialogar com as lideranças na base onde "surgem sempre dúvidas como: o que é mesmo gênero? 0 que queremos dizer quando falamos de gênero?" (SETOR NACIONAL DE GÊNER0, 2003, p. 7). Com vistas a contribuir para os debates em torno destas questões, o(a)s vário(a)s autore(a)s da cartilha, recorrendo à vasta literatura sobre o assunto, abordam as relações de gênero, o feminismo, a luta de classes, os significados do dia internacional da mulher.

É difícil encontrar uma trajetória linear que detalhe precisamente as razões que levaram o Coletivo Nacional de Mulheres a se tornar Coletivo Nacional de Gênero e menos ainda que explique a alteração deste para Setor Nacional de Gênero. Uma das coordenadoras do Setor Nacional de Gênero nos revelou que havia muita dificuldade de avançar na participação das mulheres e que era necessário que esta temática fizesse parte da própria estrutura organizativa do Movimento dividida em Setores e predominantemente ocupados por homens. Ela observa que:

aos poucos, o próprio Movimento foi descobrindo que nós só íamos avançar nesse debate da participação das mulheres se nós começássemos a discutir também com os homens, fazer essa discussão com os bomens. Então de início, nós dizíamos: nós temos que organizar as mulheres, mas nós temos que fazer esse debate em conjunto com os homens do Movimento, envolvendo eles nesse debate, trazendo a preocupação de que se nós quiséssemos avançar política e ideologicamente toda a familia, nós tínhamos que fazer esse debate (T. Setor Nacional de Gênero).

${ }^{7}$ Entrevista realizada em setembro de 2004. 
A mesma avaliação é feita por Lourdes Vicente, da direção nacional do Setor de Gênero, em entrevista publicada na página do MST: "quando começamos a discutir a questão, nos centrávamos na participação das mulheres. Depois começamos a falar sobre gênero. Nós temos presente duas questões fundamentais: a motivação de que as mulheres se tornarem sujeitos e criar condições para elas participem"». A página na internet do hoje conhecido Setor de Gênero ${ }^{9}$ - que durante muito tempo aparecia como Coletivo de Gênero - indica que houve uma evolução e que foram as experiências organizativas das mulheres nos acampamentos e assentamentos, assim como a própria vivência das lideranças femininas, que levaram ao debate relativo às questões de gênero.

Na mesma página, consta que para o Setor "a própria luta pela Reforma Agrária, criava espaços que facilitaram a participação da mulher dentro dos espaços públicos de uma maneira diferente. Isto obrigava as companheiras a participarem de espaços de discussões (grupos de famílias, os setores de acampamentos e as assembleias), que de uma forma ou de outra contribuíam para a inserção da mulher em tarefas que fugiam do cotidiano da sua atuação no espaço doméstico"10.

Um aspecto mencionado é que mais que a quantidade, o fundamental era a qualidade da participação das mulheres, o que exigia também o envolvimento dos "companheiros" e da organização de uma maneira mais ativa. Ou seja, não se trata mais de um trabalho com e/ou sobre as mulheres, mas de atividades que envolvam mulheres e homens. Na entrevista mencionada acima, Vicente destaca: "começamos a colocar que nós tínhamos que convocar os homens para o debate, porque senão nós avançávamos e os nossos companheiros não. Começamos a discutir gênero e poder. Ao longo do processo, fomos nos dando conta de que teríamos que entrar na estrutura orgânica do Movimento e colocamos a necessidade de termos pessoas responsáveis para fazer o debate"11.

As evoluções mencionadas não revelam a necessidade da alteração dos nomes, nem do que significam estas mudanças na estrutura organizativa do MST. Para T., do Setor Nacional de Gênero, nos estados desencadearam-se alguns debates que conduziram às discussões nas instâncias nacionais e culminaram na criação do Coletivo de Gênero.

\footnotetext{
${ }^{8}$ Ver em Vicente (2009).

${ }^{9}$ Algumas páginas foram retiradas do Sítio do MST no ano de 2005.

${ }^{10}$ Consultar Setor Nacional de Gênero (2004).

${ }^{11}$ Ver em Vicente (2009).
} 
E ai foi feito todo um debate no Movimento de que tinha que avançar nesse debate. Ai, o Movimento aprova em 2002 o Setor de Gênero pra fazer parte da estrutura orgânica, enquanto Movimento, o Setor de Gênero. Já tendo essa compreensão de que nós só íamos avançar nesse debate se a gente... se fosse um Setor organizado que fizesse parte das estruturas orgânicas do Movimento. Então, em 2002, foi aprovado enquanto Setor, né?

Porém, os debates sobre se há ou não necessidade de um Setor de Gênero não foram encerrados. Discute-se ainda o que é mais eficaz: o Setor ou o Coletivo?

\section{Decifrando o Setor de Gênero}

Num dos debates acerca da chamada "questão de gênero", ocorrido em reunião da Coordenação Nacional em agosto de 2003, Bogo, importante expoente do Movimento, identificou uma série de obstáculos culturais e morais ou mitos que impediam a participação efetiva das mulheres. Dentre os mitos, destaca os da inferioridade feminina; da representação masculina (ou da dependência feminina, sobretudo das mulheres casadas que, na representação social do casamento, passam a depender juridicamente de seus maridos); da autorização (ou de plenos poderes ao "chefe de família"); da falta de carisma, em que a mulher é vista como "incapaz" de realizar determinada tarefa; da herança cultural, que molda o jeito de ser menino ou menina; de preconceito, que elimina a credibilidade da palavra feminina; da aparência que determina a forma como as mulheres devem se vestir; do dever que impõe às mulheres o acato à autoridade dos maridos; da fidelidade; da moral religiosa.

Para que haja uma ruptura com estes obstáculos dentro do Movimento, segundo o autor, é preciso uma definição política com vistas a, por um lado, impulsionar "a revolução cultural e, aos poucos mudar os hábitos, costumes, tradições, formas de pensar e de agir", e por outro, edificar "uma nova moral que oriente a convivência social e política das pessoas" (BOG0, 2003, p. 10-11). Para o autor, participar politicamente depende da tomada de decisões que orientem as questões amplas e específicas, como por exemplo, garantir que as mulheres participem da composição da estrutura.

Desta forma, "a mulher só ocupará lugar na militância política se a estrutura organizativa abrir este espaço, para isto as mulheres terão que 'tomar' parte do lugar dos homens no seguinte sentido: se uma diretoria é composta por 12 
membros, costumeiramente só por homens, partes destes terão que deixar o lugar para que as mulheres possam assumi-los. Assim é com as instâncias de direção, nos setores, coletivos, núcleos e comissões" (B0G0, 2003, p. 11).

0 autor discorda quanto à necessidade de criação de um setor denominado "gênero". Para ele, esta preocupação foi trazida de fora para dentro e não se tornou necessidade política, pois, para nós, a luta de classes continua válida devendo ser feita por mulheres e homens. Segundo, porque até então "não se conseguiu decifrar o que diz e abrange o conceito 'gênero"' (BOGO, 2003, p. 12). Segundo Bogo, não se trata de relações entre o masculino e o feminino, a questão é política, como é o analfabetismo, a cooperação, etc. Desta maneira, "como não se cria um coletivo de analfabetos para discutir alfabetização, um grupo de individuais ${ }^{12}$ para debater a cooperação, um grupo de doentes para discutir a saúde", o autor considera que se torna também "limitado reunir um grupo de mulheres para discutir a participação ou simplesmente as questões de relações". Este, como os demais assuntos, é, para o estudioso, "de responsabilidade política da organização encontrar formas de desbloquear as questões culturais e morais, para tornar a mulher força viva de participação política e social" (BOGO, 2003, p. 12).

Estas discussões internas ao MST se assemelham ao problema da dupla ameaça que as mulheres representaram para vários movimentos que vislumbravam a transformação social: o atraso decorrente da ausência na esfera política e a necessidade de um esforço especial para sua emancipação. Esta dupla ameaça levou vários movimentos a privilegiarem as questões "gerais" em detrimento das "específicas". No entanto, há uma sutil diferença. A dificuldade que se observa nas ponderações de Bogo diz respeito à maneira de tratar a questão (se setor ou coletivo) e a como denominar o problema, mas não de colocá-lo para um segundo plano.

Não havendo uma definição clara do que são relações de gênero, as questões que Bogo suscita levam a refletir se a pouca participação das mulheres é: um problema de mulheres? Ou um problema de homens e mulheres? Ou um problema de gênero? Ou ainda um problema político? 0 autor admite a existência do problema e considera "importante ter coletivos que aprofundem os assuntos, subsidiem os debates com elementos que aos poucos se tornem a

\footnotetext{
${ }^{12}$ Expressão utilizada para se referir a grupos de pessoas que nos assentamentos não participam da produção coletiva.
} 
teoria da organização do MST". À medida que "a mulher começa a participar das atividades políticas e organizativas, serão discutidos e solucionados os problemas das limitações de sua participação" (BOG0, 2003, p. 12).

\section{Às TURRAS COM O CONCEITO DE GÊNERO}

A dificuldade de utilização e definição do conceito de gênero não é uma característica particular dos debates internos do MST. Este termo, apesar de ter sido utilizado anteriormente, passou a ser conhecido por meio da conceitualização de Rubin (1975) e hoje seu uso tornou-se frequente para se referir à construção social de homens e mulheres a partir da percepção do sexo biológico.

No Brasil, foi, sobretudo, a partir de Scott que o termo gênero tornou-se mais conhecido como uma forma de indicar construções culturais. "0 uso do gênero enfatiza todo um sistema de relações que pode incluir o sexo, mas não é diretamente determinado pelo sexo, nem determina diretamente a sexualidade" (1995, p. 76). Para Piscitelli, o conceito de gênero é produto da inquietação feminista quanto às causas da opressão feminina. No entanto, sua elaboração "está associada à percepção da necessidade de associar essa preocupação política a uma melhor compreensão da maneira como o gênero opera em todas as sociedades, 0 que exige pensar de maneira mais complexa o poder" (PISCITELLI, 2002, p. 21). Gênero passa a ser definido como um elemento constitutivo das relações sociais (e, portanto, de poder) a partir das diferenças percebidas entre os sexos. Cabe ressaltar a ideia de gênero como historicamente situado, o que permite a desconstrução de muitos significados vinculados à natureza ou à "essência" feminina.

Se a utilização do conceito de gênero foi amplamente acolhida como contribuição para "uma nova metodologia de análise por muitos de seus usuários do campo intelectual brasileiros" (MACHAD0, 1998, p. 108), como pode ser exemplificado pelas ponderações de Bogo (2003), a unanimidade entre intelectuais não é tanta assim. Identificam-se dificuldades semânticas para seu uso e na maioria das vezes gênero acaba sendo utilizado como substituto da categoria sexo ou simplesmente como sinônimo de homem e de mulher (MORAES, 1998). As mesmas dificuldades, aliás, foram encontradas pelas feministas e/ou pesquisadoras francesas em função da polissemia do termo gênero em francês. Em sua acepção de sexo social distinto do sexo biológico, o uso de gênero causava incômodo, pois a cada utilização "sempre era necessário defini-lo" (LÖWY \& ROUCH, 2003, p. 5). 
A incessante busca de um conceito que pudesse ir além da ênfase sobre 0 econômico, deu fôlego aos estudos de gênero ao mesmo tempo em que contribuiu para um deslocamento de intelectuais feministas para os espaços acadêmicos, o que criou um fosso entre teoria e militância (GONÇALVES, 2009).

Marchando na contramão deste processo, as mulheres envolvidas na luta pela terra do MST apropriam-se do conceito de gênero (re)politizando-o, procurando (re)estabelecer os laços com as bases materiais. Lançam mão do conceito não para falar em mulher e/ou homem genérica(0), mas, como propõe Saffioti (1994), para abordar relações sociais situadas historicamente. De outra forma tornaria difícil, por exemplo, analisar os conflitos de classe que separam a mulher, trabalhadora rural, Diolinda Alves ${ }^{13}$ da mulher, fazendeira, Tânia Tenório de Farias ${ }^{14}$ ambas inseridas no embate político da luta pela terra no Pontal do Paranapanema. 0 capitalismo que as separam é o mesmo que faz com que uma classe concentre em suas mãos a maior parte da riqueza social, enquanto a outra se torna cada vez mais miserável e espoliada. Lutar pela igualdade entre os gêneros e, logo, derrubar a hierarquia de poder (dentro e fora do Movimento), implica combater a ordem econômica que se reproduz produzindo desigualdades.

0 que não significa que não haja conflitos no interior de uma mesma classe. A este respeito, a integrante do Setor de Gênero, Lourdes Vicente, apesar de observar que as mulheres inseridas na luta pela terra são duplamente oprimidas - pela exploração do capital e por ser mulher - e de denunciar que as condições de vida das mulheres que moram nos acampamentos e assentamentos são piores que as dos homens, enfatiza que "dentro do Movimento há, de certa forma, uma reprodução de papéis sociais". Todavia, destaca a diferença entre as mulheres que atuam no interior do MST. Para ela, "as Sem Terra têm uma chance de se reconhecerem oprimidas e de construírem uma identidade com a discussão de seu papel social, questionando e problematizando", e complementa que a "própria forma de organização do Movimento leva essas mulheres a buscarem a superação das desigualdades, tanto econômica como de participação no MST"15.

\footnotetext{
${ }^{13}$ Conhecida liderança do MST no Pontal do Paranapanema; tornou-se um dos símbolos da luta pela Reforma Agrária no Brasil. Evitando qualquer tipo de personalismo, citamos esta personagem em função de sua visibilidade nacional, mas poderíamos mencionar as tantas Míriams, Marias e Joanas...

${ }^{14}$ Ex-presidente da UDR (União Democrática Ruralista), entidade de organização dos latifundiários.

${ }^{15}$ Ver em Vicente (2009).
} 


\section{Algumas CONSIDERAÇÕES INCONCLUSAS}

Sem perder de vista o caráter de classe que a própria luta pela terra impõe, a trajetória das mulheres do MST é exemplo significativo de como dentro dos diferentes espaços se pode desconstruir e reconstruir as chamadas relações de gênero. Recorrer ao conceito de gênero tornou-se uma necessidade até mesmo pela maneira como o debate foi introduzido no MST: os coletivos de mulheres, que acenavam para uma discussão em torno de questões ditas "específicas", deram surgimento aos coletivos de gênero que, por sua vez, fizeram emergir os setores de gênero, indicando uma alteração nos objetivos e colocando em evidência 0 anseio por transbordar a discussão para além das fronteiras de gênero, derrubando por vezes as trincheiras machistas que resistiam (e resistem!) no interior do Movimento.

Em meio aos constantes debates sobre conceitos e nomenclaturas, o Setor Nacional de Gênero foi traçando suas diretrizes políticas dentro do Movimento dos Trabalhadores Rurais Sem Terra. Num movimento dinâmico de (re)politização e, não sem provocar tensões no que diz respeito à militância feminina, o Setor foi definindo as ações tanto nas Instâncias como também e, sobretudo, nos espaços dos acampamentos e assentamentos, onde, como está na canção, se encontram as Roses, as Rosas e as Margaridas que fazem a primavera da luta pela terra do MST.

\section{REFERÊNCIAS}

BOGO, Ademar. A organicidade como parte da cultura. Texto para debate sobre a organicidade do MST na reunião da Coordenação Nacional de 13 a 17 de agosto, 2003, mimeo.

BONFIN, Cristiane. 0 jeito feminino de lutar pela reforma agrária. Jornal 0 Povo. 08 de março, 2002. Disponível em: http://www.opovo.com/

BRUMER, Anita \& ANJOS, Gabriele dos. Relações de gênero em assentamentos: a noção de empoderamento em questão. In: LOPES, Adriana \& BUTTO, Andrea. (orgs.). Mulheres na Reforma Agrária. A experiência recente no Brasil. Brasília: MDA, 2008.

COLETIVO NACIONAL DE MULHERES DO MST. A questão da mulher e o MST. São Paulo: MST, 1996. 
Compreender e construir novas relações de gênero. São Paulo: MST, 1998.

COLETIVO NACIONAL DE GÊNERO DO MST. (2000). Mulher Sem Terra. São Paulo: MST.

DEERE, Carmen. Os direitos da mulher à terra e os movimentos sociais rurais na reforma agrária brasileira. Revista de Estudos Feministas, Florianópolis, vol. 12, n. $1,2004$.

ESMERALDO, Gema. Ruídos com marcas de transgressões ancoradas em Mulheres Assentadas. In: LOPES, Adriana \& BUTTO, Andrea. (orgs.). Mulheres na Reforma Agrária. A experiência recente no Brasil. Brasília: MDA, 2008.

FRANCO, Maria. A luta pela terra sob enfoque de gênero: os lugares da diferença no Pontal do Paranapanema. Tese de Doutorado, Geografia, Universidade Estadual Paulista, Presidente Prudente, 2004.

GONÇALVES, Renata. Vamos acampar? A luta pela terra e a busca pelo assentamento de novas relações de gênero no MST do Pontal do Paranapanema. Tese de Doutorado, Ciências Sociais, Instituto de Filosofia e Ciências Humanas, Universidade Estadual de Campinas, 2005.

. Sem pão e sem rosas: do feminismo marxista impulsionado pelo Maio de 1968 ao academicismo de gênero. Lutas Sociais, São Paulo, n. 21/22, 2009.

JORNAL SEM TERRA. Sem a luta das mulheres, as conquistas ficam pela metade. Novembro, 1995.

. O MST deve lutar também contra o machismo. Março, 1996.

MACHADO, Lia Zanota. Gênero, um novo paradígma? Cadernos Pagu, Campinas, n. 11, 1998 .

MORAES, Maria Lygia Quartim de. Usos e limites da categoria gênero. Cadernos Pagu, n. 11, Campinas, 1998.

MST. Normas gerais do MST. São Paulo: MST, 1989.

. Documento Básico do MST. São Paulo: MST, 1993.

PAULILO, Maria Ignez. 0 peso do trabalho leve. Ciência Hoje, Rio de Janeiro, vol. 5, n. 28, 1987.

PAVAN, Dulcinéia. As Marias Sem-Terras: trajetória e experiências de vida de mulheres assentadas em Promissão/SP (1985/1996). Dissertação de Mestrado, História, Pontifícia Universidade Católica de São Paulo, 1998. 
PISCITELLI, Adriana. Re-criando a (categoria) mulher? In: ALGRANTI, Leila Mezan (org.). A prática feminista e o conceito de gênero. Col. Textos didáticos, n. 48. Campinas: Unicamp/IFCH, 2002.

RUA, Maria das Graças \& ABRAMOVAY, Miriam. Companheiras de luta ou "coordenadoras de panelas"? As relações de gênero nos assentamentos rurais. Brasília: UNESCO, 2000.

RUBIN, Gayle. The traffic in women: notes on the 'political economy' of sex'. In: REITER, Rayna. (org.). Toward an antropology of women. Nova Iorque: Montly Review Press, 1975.

SAFFIOTI, Heleieth. Posfácio: conceituando o gênero. In: SAFFIOTI Heleieth \& MUÑOZ-VARGAS, Monica. (orgs). Mulher brasileira é assim. Rio de Janeiro: Rosa dos Tempos, 1994.

SCOTT, Joan W. Gênero: uma categoria útil de análise histórica. Educação \& Realidade. Porto Alegre, v. 2, n. 20, 1995.

SETOR NACIONAL DE GÊNERO. Construindo novas relações de gênero: desafiando relações de poder. São Paulo: MST, 2003.

. Movimento dos Trabalhadores Rurais Sem Terra, 2004. Disponível em: www.mst.org.br/mstsp/sgen.htm Acesso em 14 de julho de 2004.

SILVA, Cristiani. Bereta da. Homens e mulheres e movimento: relações de gênero e subjetividade no MST. Florianópolis: Momento Atual, 2004.

. Relações de gênero e subjetividade no devir MST. Revista de Estudos Feministas, Florianópolis, vol. 12, n. 1, 2004a.

STÉDILE, João Pedro \& FERNANDES, Bernardo Mançano. Brava gente: a trajetória do MST e a luta pela terra no Brasil. São Paulo: Perseu Abramo, 1999.

VICENTE, Lourdes. Mulher sem terra na luta por reforma agrária: entrevista. MST. Disponível em: http://www.mst.org.br/node/2964. Acesso em novembro de 2009.

WOORTMANN, Ellen. 0 saber tradicional camponês e inovações. In: OLIVEIRA, Ariovaldo Umbelino \& MARQUES, Marta Inez Medeiros (orgs.). O campo no século XXI: território de vida, de luta e de construção da justiça social. São Paulo: Casa Amarela/ Paz e Terra, 2004. 